SANDIA REPORT

SAND 2011-6723

Unlimited Release

Printed September 2011

\title{
Earthquake Warning System for Infrastructures - A Scoping Analysis
}

Theresa J. Brown, Andjelka Kelic, Kevin L. Stamber, Nancy S. Brodsky, Eric D. Vugrin, Thomas F. Corbet, Jr., William E. Fogleman, and Sharon L. O'Connor

Prepared by

Sandia National Laboratories

Albuquerque, New Mexico 87185 and Livermore, California 94550

Sandia National Laboratories is a multi-program laboratory managed and operated by Sandia Corporation, a wholly owned subsidiary of Lockheed Martin Corporation, for the U.S. Department of Energy's National Nuclear Security Administration under Contract DE-AC04-94AL85000.

Approved for public release; further dissemination unlimited.

\section{Gandia National Laboratories}


Issued by Sandia National Laboratories, operated for the United States Department of Energy by Sandia Corporation.

NOTICE: This report was prepared as an account of work sponsored by an agency of the United States Government. Neither the United States Government, nor any agency thereof, nor any of their employees, nor any of their contractors, subcontractors, or their employees, make any warranty, express or implied, or assume any legal liability or responsibility for the accuracy, completeness, or usefulness of any information, apparatus, product, or process disclosed, or represent that its use would not infringe privately owned rights. Reference herein to any specific commercial product, process, or service by trade name, trademark, manufacturer, or otherwise, does not necessarily constitute or imply its endorsement, recommendation, or favoring by the United States Government, any agency thereof, or any of their contractors or subcontractors. The views and opinions expressed herein do not necessarily state or reflect those of the United States Government, any agency thereof, or any of their contractors. 
SAND 2011-6723

Unlimited Release

Printed September 2011

\title{
Earthquake Warning System for Infrastructures - A Scoping Analysis
}

\author{
Theresa J. Brown, Andjelka Kelic, Thomas F. Corbet, Jr, \\ and Sharon L. O'Connor \\ Policy and Decision Analytics, 6924 \\ Kevin L. Stamber \\ System Research, Analysis and Applications, 6132 \\ Nancy S. Brodsky and Eric D. Vugrin \\ Resilience and Regulatory Effects, 6921 \\ Sandia National Laboratories \\ P.O. Box 5800 \\ Albuquerque, New Mexico 87185-0783 \\ William E. Fogleman \\ GRIT, Inc. \\ Albuquerque, New Mexico
}

\begin{abstract}
This report provides the results of a scoping study evaluating the potential risk reduction value of a hypothetical, earthquake early-warning system. The study was based on an analysis of the actions that could be taken to reduce risks to population and infrastructures, how much $t$ time would be required to take each action and the potential consequences of false alarms given the nature of the action. The results of the scoping analysis indicate that risks could be reduced through improving existing event notification systems and individual responses to the notification; and production and utilization of more detailed risk maps for local planning. Detailed maps and training programs, based on existing knowledge of geologic conditions and processes, would reduce uncertainty in the consequence portion of the risk analysis. Uncertainties in the timing, magnitude and location of earthquakes and the potential impacts of false alarms will present major challenges to the value of an early-warning system.
\end{abstract}




\section{Contents}

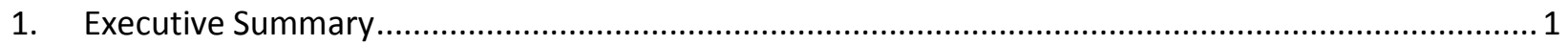

Scope of Work

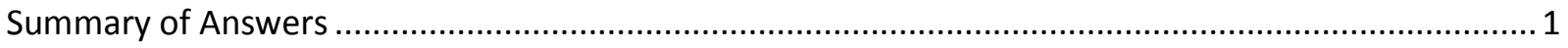

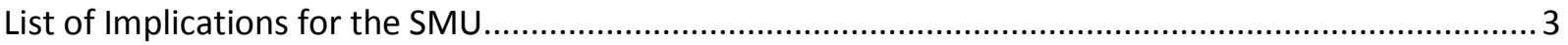

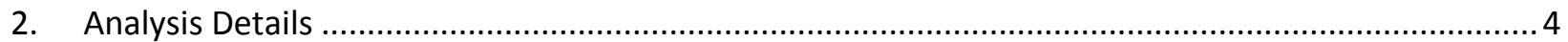

Question 1: What can we learn from existing early warning systems (for earthquakes and other

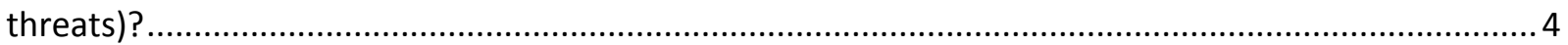

Question 2: What could be done, in what timeframe, to reduce risks? ................................................ 7

Question 3: How much warning time is needed? .......................................................................... 10

Question 4: What is an acceptable confidence level? (Encompasses the questions what is the impact of uncertainty and what is the cost of false alarms?) ......................................................................... 11

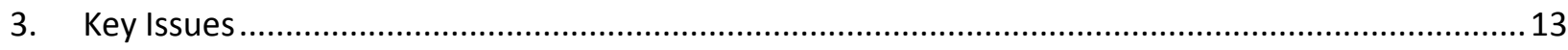

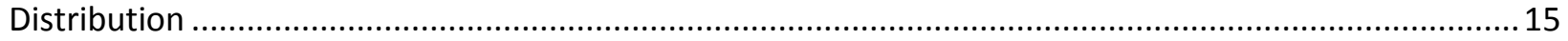




\section{Executive Summary}

\section{Scope of Work}

Len Napolitano, Director of Computer Sciences and Information Systems, asked Pablo Garcia, Senior Manager of Interdependency and Consequence Effects, to assemble a team to answer the following questions regarding the value of an earthquake early warning system for infrastructures:

- What is the impact of uncertainty?

- How much warning time is needed?

- What is the cost of false alarms?

- What is an acceptable confidence level?

The team added the following questions to help address the initial study questions:

- What could be done, in what timeframe, to reduce risks?

- What can we learn from existing early warning systems (for earthquakes and other threats)?

\section{Summary of Answers}

- What is the impact of uncertainty? Existing earthquake warnings provide lots of lead time but are highly uncertain; leading to inconsistencies in how decisions are made regarding building codes, the installation of protective measures and levels of preparedness (Figure 1). Event notification systems, which provide certainty, are the current mechanism for warning the public and changing infrastructure operations. Even with certainty, the response and preparedness vary by location and from individual to individual.

- How much warning time is needed? Warning time requirements will vary depending on the options that exist for protecting the population and infrastructures. The options evaluated in this study are summarized in Table 1 on the next page.

- What is the cost of false alarms? The answer to this question also depends on the options that exist for protecting the population and infrastructures, the timing of and the location where the false alarm occurs. General categories of consequences for false alarms are included in the summary table on the next page.

- What is an acceptable confidence level? The confidence level required for implementation of specific options will depend on the relationship between costs and benefits for that option and the characteristics (e.g., economic activity, transportation modes, evacuation capacity, and population capabilities) of the region where the option would be implemented. Answers to this question will also be subject to the resources and risk management decisions in each region. We provide a qualitative, general cost-benefit analysis for each infrastructure. There are too many regions and uncertainties to provide quantitative results at this point.

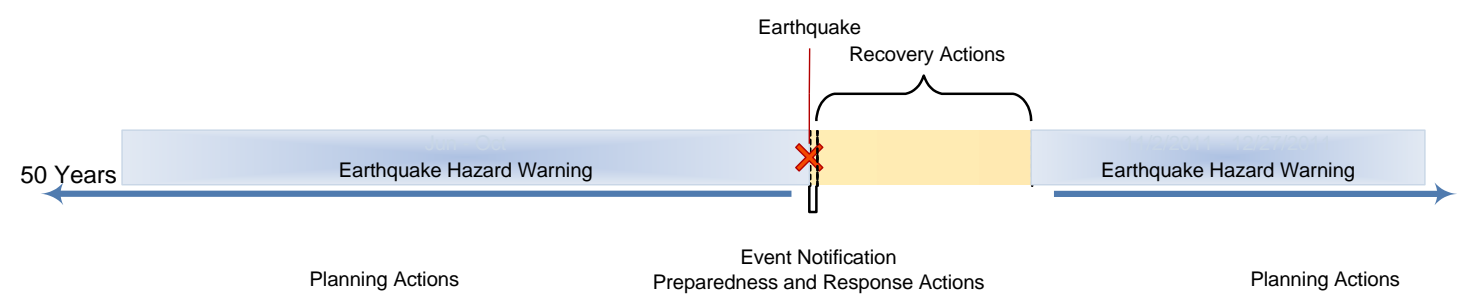

Figure 1. Event Notification, Preparedness and Response Actions 
Table 1. Risk Reduction Factors

\begin{tabular}{|c|c|c|c|c|c|}
\hline What can be done to reduce risk? & Benefit & In what time frame? & $\begin{array}{l}\text { Supporting Technology/Analysis } \\
\text { Requirements }\end{array}$ & Alternative Strategies & False Alarm Implications \\
\hline Alerts & tbd & tbd & $\begin{array}{l}\text { training, notification system } \\
\text { including communication system } \\
\text { capacity, processes and planning, } \\
\text { detailed risk/benefit analyses }\end{array}$ & $\begin{array}{l}\text { insitu shelters (building re- } \\
\text { design, retrofitting), improve } \\
\text { event notification, reduce } \\
\text { uncertainty in hazards warning }\end{array}$ & $\begin{array}{l}\text { disruption of activities, reducing } \\
\text { compliance, accidents }\end{array}$ \\
\hline Evacuate buildings & $\begin{array}{l}\text { reduce deaths due to building } \\
\text { collapse }\end{array}$ & & $\begin{array}{l}\text { training, notification system } \\
\text { including communication system } \\
\text { capacity, processes, planning }\end{array}$ & $\begin{array}{l}\text { insitu shelters (building re- } \\
\text { design, retrofitting), improve } \\
\text { event notification }\end{array}$ & $\begin{array}{l}\text { disruption of operations, impacts } \\
\text { to supply chain, reducing } \\
\text { compliance, accidents }\end{array}$ \\
\hline schools & $\begin{array}{l}\text { reduce deaths of students, } \\
\text { teachers and staff }\end{array}$ & minutes & & & + fear \\
\hline hospital & $\begin{array}{l}\text { reduce deaths of staff and } \\
\text { visitors, possibly patients }\end{array}$ & hours - days & $\begin{array}{l}\text { transportation system, alternate } \\
\text { facilities, emergency medicine } \\
\text { capacity }\end{array}$ & & + reduced quality of care \\
\hline Stop hazardous processes & $\begin{array}{l}\text { reduce health and } \\
\text { environmental impacts due to } \\
\text { the uncontrolled release of } \\
\text { hazardous material }\end{array}$ & & $\begin{array}{l}\text { training, notification system } \\
\text { including communication system } \\
\text { capacity, processes, planning }\end{array}$ & $\begin{array}{l}\text { redesign process/facilities } \\
\text { (harden against eq of very large } \\
\text { magnitude), relocate out of } \\
\text { eq/high hazard zones }\end{array}$ & $\begin{array}{l}\text { disruption of operations, impacts } \\
\text { to supply chain, reducing } \\
\text { compliance, accidents }\end{array}$ \\
\hline $\begin{array}{l}\text { seismic and remote controlled } \\
\text { shutoff valves installed in pipelines }\end{array}$ & & seconds & & $\begin{array}{l}\text { seismic only, strategic reserves } \\
\text { of fuel }\end{array}$ & $\begin{array}{l}\text { + disruption in flow of fuels, } \\
\text { chemicals }\end{array}$ \\
\hline stop trains & & minutes to seconds & & notification system and process & \\
\hline nuclear power plant & & minutes to hours & & & + electric power supply reduction \\
\hline reroute bridge traffic & $\begin{array}{l}\text { reduce deaths due to bridge } \\
\text { collapse }\end{array}$ & minutes to hours & $\begin{array}{l}\text { rerouting system, bridge closure } \\
\text { system }\end{array}$ & & \\
\hline empty tanks on long legs & & hours to days & & transportation capacity & $\begin{array}{l}\text { + disruption in availability of fuels } \\
\text { chemicals }\end{array}$ \\
\hline chemical plant safe shut-down & & days (24-72 hours) & & $\begin{array}{l}\text { containment redesign, stockpiles } \\
\text { to offset disruptions }\end{array}$ & + long-disruption \\
\hline Evacuate areas & $\begin{array}{l}\text { reduce deaths, injuries and } \\
\text { population in the damage area } \\
\text { during response and recovery }\end{array}$ & & $\begin{array}{l}\text { evacuation/transportation } \\
\text { system, } \\
\text { compliance/enforcement } \\
\text { system, displacement } \\
\text { assisstance }\end{array}$ & increased preparedness & $\begin{array}{l}\text { long-term economic disruption, } \\
\text { reducing compliance }\end{array}$ \\
\hline small population & & hours to day & & & \\
\hline high density population & & weeks & & & + high economic consequences \\
\hline Facility redesign & & years & & & potentially higher building costs \\
\hline
\end{tabular}




\section{List of Implications for the SMU}

\section{- Identified Potential Technological Solutions Independent of an Alert System}

1. Improved event notification systems

2. Improved traffic control systems for bridge closure, improving evacuation, response and recovery capabilities

3. Decision support systems for local to national earthquake planning, preparedness, response and recovery

4. Cost effective, in-situ shelters

- Analytical Products:

1. Training programs

2. Improved evacuation design (this analytical product could be stand alone but it would also be needed to design improved traffic control systems and event notification systems)

3. Improved disaster recovery design

4. Risk and mitigation analyses to support local to national planning and preparedness projects, activities and decisions (Figure 2)

5. Shelter design

- Potential Customers:

1. National and Regional Planning - DHS/FEMA, HITRAC, NCS; Sector Specific Agencies/ HHS, DOT, DOE, EPA

2. Local and Regional Planning - Local Emergency Planning Coordinators (LEPCs), Emergency Managers, State Homeland Security Organizations, Planning/Zoning Commissions

\section{- Collaborators/Partners:}

1. Corporate partners for technology manufacturing/fielding

2. Academic programs for urban planning and design, emergency response planning

3. USGS and state geologist/seismologist partners for improved geologic hazards mapping

- Capability Needs:

1. Local to regional evacuation models

2. Local emergency condition traffic models

3. Detailed earthquake hazards maps

4. Improved ground-motion propagation algorithms (to speed-up and improve event notification systems)

5. Models of building response and failures due ground motion 


\section{Analysis Details}

\section{Question 1: What can we learn from existing early warning systems (for}

earthquakes and other threats)?

Long-term Advanced Earthquake Warning - The U.S. Geological Survey (USGS) issues seismic hazard maps (Figure 2) and more detailed ShakeMaps; ${ }^{1}$ these maps provide a model-based warning system for earthquakes with associated uncertainties. ShakeMaps are provided following an event and for scenariobased planning. ShakeMaps show perceived, measured, and interpolated ground motions (peak ground acceleration, peak velocity) and qualitative estimates of damage (none to very heavy). The earthquake hazard maps show the distribution of peak ground accelerations with a specified probability of occurrence (generally 2,5 , or $10 \%$ ) in a given time frame (generally 50 years). The probability and magnitudes are based on geologic conditions, and the distribution of ground motion is based on the bedrock physical properties. The USGS earthquake hazard maps are used to inform decisions about building codes and permits. Building codes are not uniform or consistent from location to location. Even within the same location; the regulations have changed over time with older buildings meeting different standards than newer construction. Uncertainty in the timing, magnitude, and location of seismic activity leads to variability in regulations and heterogeneity in the perception of earthquake risks. The U.S. Department of Transportation (DOT) uses ShakeMaps to design the bridge monitoring system and set bridge inspection priorities following an event. These maps are also used in setting insurance rates and land-use planning decisions.

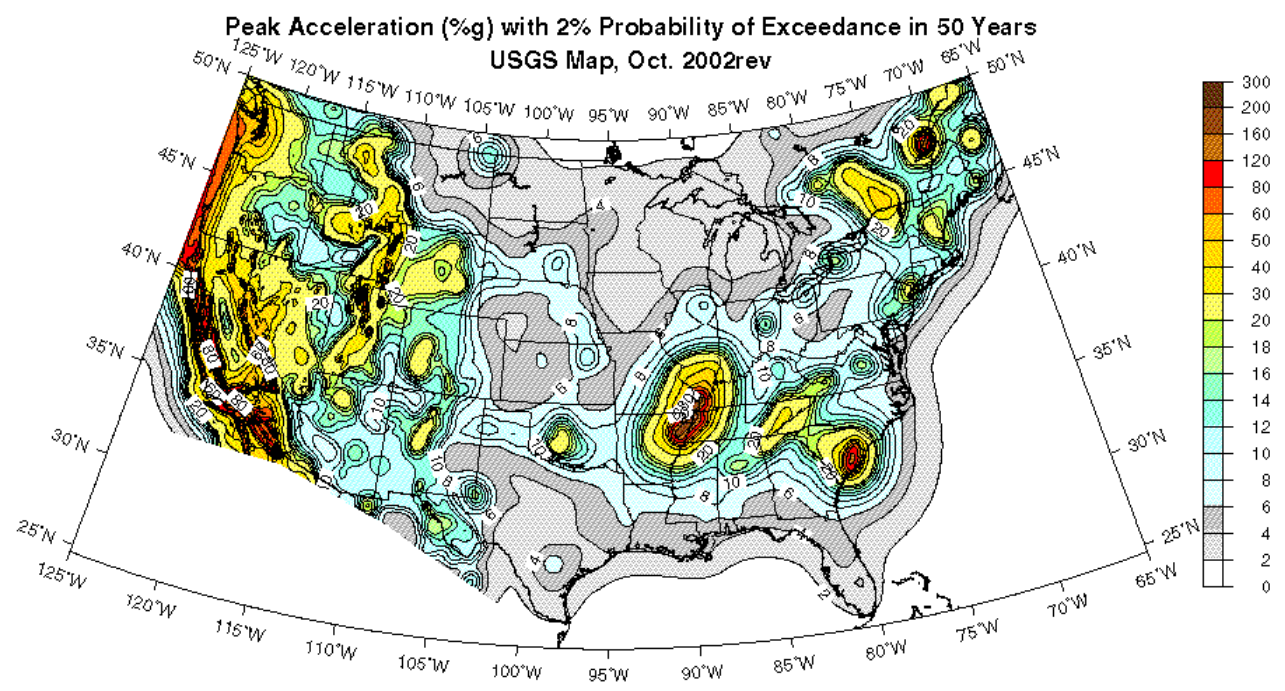

Figure 2. Seismic Hazard Map for the Continental US ${ }^{2}$

The Federal Emergency Management Agency (FEMA) provides a tool - the Hazards U.S. MultiHazard (HAZUS-MH) ${ }^{3}$ - for estimating potential earthquake impacts based on building types, time of

${ }^{1}$ USGS Earthquake Hazards Program, http://earthquake.usgs.gov/hazards/, accessed May 4, 2011.

${ }^{2}$ USGS Earthquake Hazards Program, http://earthquake.usgs.gov/hazards/, accessed May 4, 2011. 
day the event occurs, and the event characteristics. (HAZUS-MH uses ShakeMap input for ground motion estimates.) This FEMA tool is primarily an empirical model of damage, secondary hazards (fire), and population locations as a function of time of day. HAZUS-MH also projects population displacement due to loss of shelter (due to damage from ground motion and fire), population casualties (fatalities and by severity of injury), and damage to utilities. HAZUS is generally used for preparedness purposes (drills, emergency services planning, and training).

Earthquake Notification - Once seismic activity begins, broadcast and social networks inform the population of the event. In Japan, where they have automated notification and certain systems have seismic-wave detection, actions can be taken in the few seconds (generally 0.1 to $15 \mathrm{sec}$, depending on the location relative to the earthquake and earthquake magnitude) before the surface waves arrive at the location. ${ }^{4}$ Seismic waves move at different rates through different materials. Compression waves (P waves) travel the fastest $\left(\mathrm{V}_{\mathrm{p}}\right.$ generally $\left.5.5-7 \mathrm{~km} / \mathrm{s}\right)$ through the earth's crust; hence they are used to trigger alarms and automated protective measures. Surface waves (Love and Rayleigh) are the slowest (traveling at speeds of 1 to $5 \mathrm{~km} / \mathrm{s}$ ) and can be the most damaging. ${ }^{5}$ Given that Rayleigh waves travel at about half the speed of $\mathrm{P}$ waves, the amount of time to react can be estimated as a function of the distance from the epicenter (Figure 3). Note, however, that the area damaged and the causes of damage within that area will vary due to differences in the geologic and structural conditions, the magnitude and depth of the earthquake, and location relative to secondary events triggered by the earthquake (e.g., fire, landslide, tsunami, liquefaction).

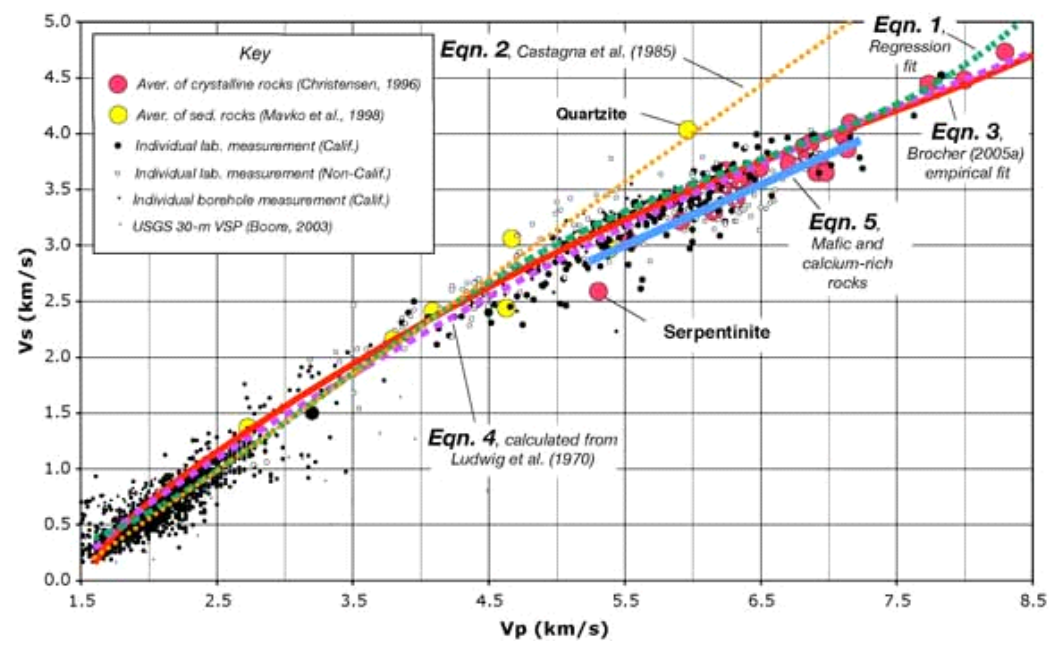

Figure 3. Examples Sheer Wave Velocity ( Vs) versus Compression Wave Velocity (Vp) for Common Rock Types ${ }^{6}$

\footnotetext{
${ }^{3}$ FEMA Hazus Program, http://www.fema.gov/plan/prevent/hazus/, accessed May 4, 2011.

${ }^{4}$ Details on earthquake alarms: http://www.sdr.co.jp/papers/14wcee/14wcee_p-wave_alarm_systems.pdf and http://www.sdr.co.jp/papers/14wcee/14wcee p-wave alarm systems.pdf, accessed May 4, 2011.

${ }^{5}$ http://eqseis.geosc.psu.edu/ cammon/HTML/Classes/IntroQuakes/Notes/waves and interior.html, accessed May 4, 2011.

${ }^{6}$ From Compression and Shear Wave Velocity Versus Depth in the San Francisco Bay Area, CA, http://pubs.usgs.gov/of/2005/1317/of2005-1317.pdf, accessed May 4, 2011.
} 
Another Reason Why Location Matters - The area over which damage occurs and ground motion will be felt depends on the regional geologic conditions. Risk perception and therefore preparedness will also vary as a function of the frequency of events in the region or similar regions (Figure 4).

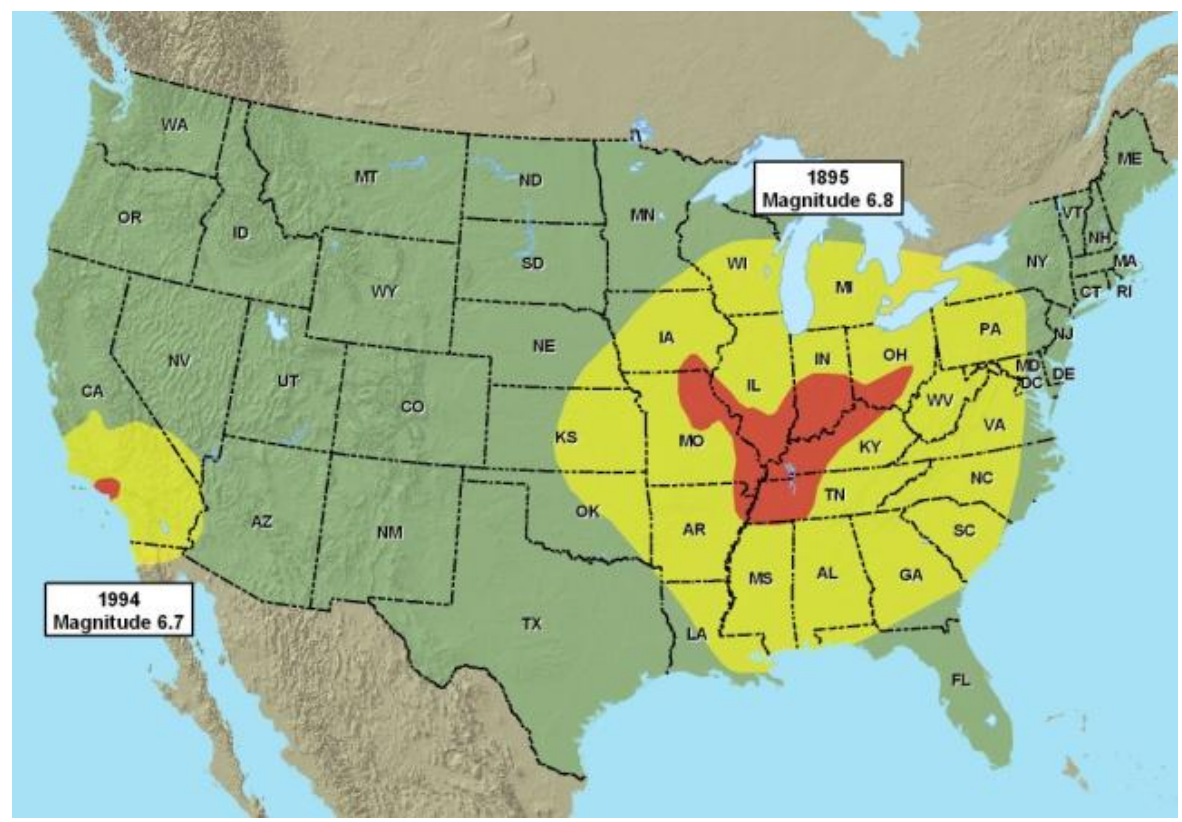

Figure 4. Comparable Magnitude Earthquakes. The 1895 NMSZ earthquake with the 1994 Northridge (CA) Earthquake.7 Red indicates regions of minor to major damage to buildings, and yellow indicates regions in which shaking can be felt

Tsunami Warning System - Tsunamis are more likely to follow large (generally greater than moment magnitude 7), shallow earthquakes below the seabed. There is a tsunami warning system for events in the Pacific Ocean. The seismic event triggers the warning, but the time to act depends on the location relative to the event. The actions taken in response to the warning are evacuating people from the low-lying coastal areas that are at risk and shutting down nuclear power plants. A warning time of minutes to hours provides time for people to move toward safer locations and for automated adjustments to infrastructure operations that reduce risks.

Hurricane Warning System $^{8}$ - The National Oceanic and Atmospheric Administration (NOAA) uses atmospheric and ocean data (winds, temperatures, and humidity) and models to provide hurricane warnings. The hurricane warning system provides probabilities of hurricane force winds (by location over time) and the expected magnitude of winds and potential storm surge height at landfall. Longterm preparedness can be guided by pre-event Sea, Lake, and Overland Surges from Hurricanes $(\mathrm{SLOSH})^{9}$ model results that provide a maximum-of-maximums estimate of inundation as a function of hurricane category. These warnings evolve over time as conditions change and become more certain. If the magnitude of the hurricane or projected rainfall is great enough (based on modeled damages, but there is no fixed trigger), state and local agencies implement evacuation plans for

\footnotetext{
${ }^{7}$ Schweig, E., J. Gomberg, and J. W. Hendley II, 1995. Whole Lotta Shakin' Goin' On. U.S. Geological Survey Fact Sheet 168-95.

${ }^{8}$ NOAA National Hurricane Center http://www.nhc.noaa.gov/, accessed May 4, 2011.

${ }^{9}$ National Hurricane Center SLOSH Model, http://www.nhc.noaa.gov/HAW2/english/surge/slosh.shtml, accessed May 4, 2011.
} 
specified areas about 48 hours before projected landfall. Evacuation plans are based on experience and models. Infrastructures prepare in different ways. For example, oil and gas production is shut-in and crews are evacuated from offshore rigs about 48 hours before the hurricane is expected in the area (time before landfall will depend on the velocity of the storm), chemical and nuclear facilities are shuttered (safe shut down) about 48 hours prior to landfall, additional fuel and currency are moved into the region, and emergency supplies are pre-positioned.

Tornado Warning System - This national warning system is issued by the National Weather Service ${ }^{10}$ and further broadcast by television, radio, and subscription news services. Weather alert radios and local warning sirens further enhance this system, which provides different levels of warning (tornado watches) and event notification (tornado warnings indicate funnel clouds have been spotted) that provide seconds to minutes of time for individuals to move to safer locations. Schools drill for tornado events. Individuals vary in their responses. Areas with higher frequency of tornados sometimes have designated storm shelters in communities.

\section{Question 2: What could be done, in what timeframe, to reduce risks?}

What can be done is a function of the lead time provided by the warning. There are three categories of activities: Protection, Preparedness, and Response. The appropriate activities are dependent on the amount of lead time afforded by the warning.

Protection (years) - With a long lead time of years provided by predictive modeling and knowledge of geologic and seismic conditions, protection activities that can be accomplished include:

- Decrease building and facility fragility (to protect people from building collapse and hazardous substances) through building codes and plant and infrastructure designs for earthquakes and other hazards. ${ }^{11}$ (Note there will be competing issues: above-ground infrastructure (telephone and power lines, windows, buildings) is more vulnerable to wind (tornados), but below-ground facilities and equipment are more vulnerable to flooding. In some cases, underground utilities (e.g., water wells, pipeline) can be more vulnerable to earthquakes.)

- Move vulnerable structures (buildings and infrastructure) out of zones where hazards (liquefaction, large magnitude events, flooding) or construction costs make prevention infeasible (to reduce damage and perturbations).

- Develop stockpiles to offset the anticipated disruptions in critical supplies.

- Ensure sufficient back-up power supplies will be available for critical functions.

- Install protection systems. In pipelines, install numerous cut-off valves to limit the amount of material that is spilled or lost in the event of a rupture. There are motion- and pressure-sensitive valves that will close and thereby reduce the amount of material spilled. These valves are expensive, so their use is neither ubiquitous nor frequent. There is currently a bill in California that, if passed would require automatic and remote-controlled shut-off valves throughout the gas pipeline system. ${ }^{12}$ Reducing the distance between valves in a natural gas pipeline (transmission or distribution) reduces the amount of fuel available for fires. If it were feasible to use these valves in hazardous liquids pipelines, environmental hazard cleanup costs, lost product, and recovery times could be reduced. Seismic shut-off valves for homes and businesses (i.e., at the distribution

\footnotetext{
${ }^{10}$ NOAA National Weather Service, http://www.nws.noaa.gov/, accessed May 4, 2011.

11 "Passive Control For Seismic Protection Of Critical Components In Industrial Process Plants," Ciampi et al., Proc. of the 13th World Conference on Earthquake Engineering, 2004, www.iitk.ac.in/nicee/wcee/article/13 1836.pdf, accessed May 4, 2011.

12 "Tougher pipeline safety standards closer in California", Central Valley Business Systems Times, http://www.centralvalleybusinesstimes.com/stories/001/?ID=18072, accessed May 4, 2011.
} 
level) are available and cost about $\$ 100$ to $\$ 1000$ each (depending on size). California building codes require seismic shut-off valves.

- Replace/modify equipment to reduce vulnerability. At chemical processing facilities, the greatest number of documented failures (resulting from earthquakes) are: ${ }^{13}$

○ Liquid storage tanks - These tanks are more susceptible to damage because sloshing of tank contents from ground shaking will affect (weaken) the walls of the tank more than for tanks containing gas and solids.

○ Leg-supported heavy structures - These structures are suspended above ground by support legs. Ground shaking can cause failure of the legs, resulting in collapsed structures (Figure 5).

- Pipes - Underground pipes are especially prone to damage (compared to above-ground pipes.) Detection of pipe damage and leaks is more difficult for underground pipes. Pipes transporting chemicals often use ceramics, glass, or similarly brittle material to prevent corrosion; making them more vulnerable than typical all-metal pipes.
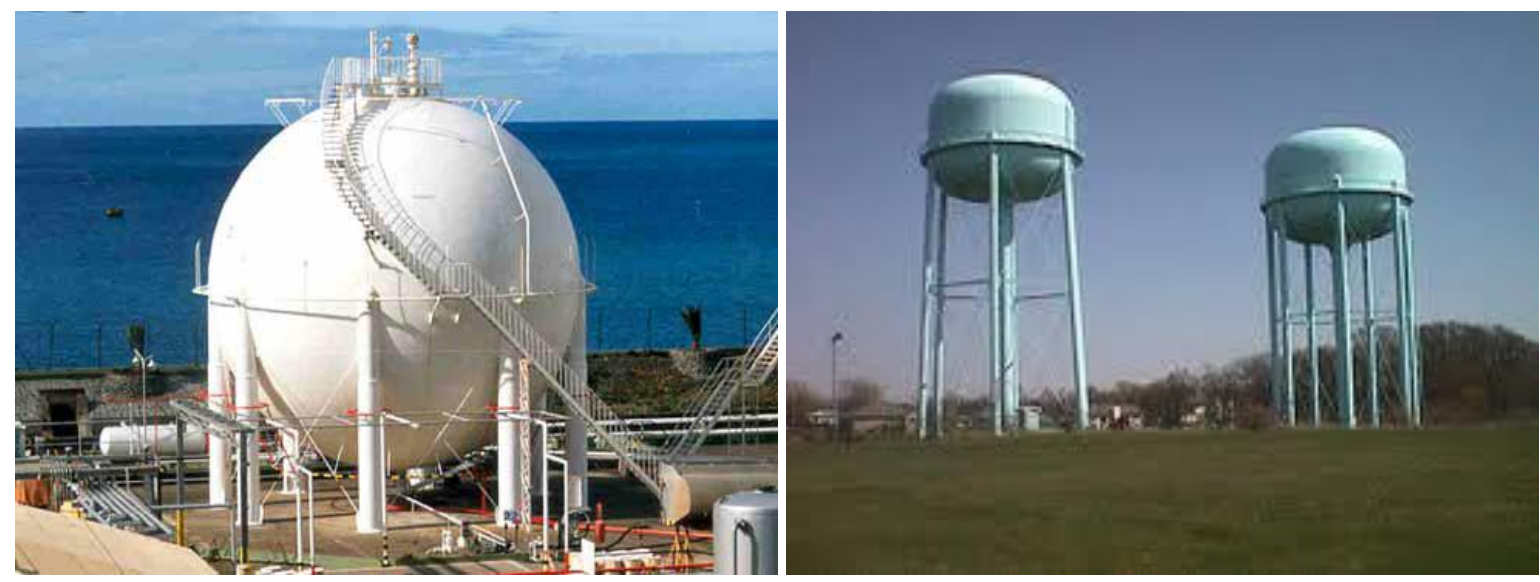

Figure 5. Butane Storage Tank and Water Towers with Legs

Preparedness - Preparedness actions are what can be done during the period of Event Notification (seconds for ground motion, seconds to hours for tsunami, days for hurricanes). The following are the types of actions that can be taken in those time periods. Planning and implementing the systems necessary to perform these actions could take years.

- Safe shut-down for hazardous operations - Valves can be closed in seconds, fast-moving vehicles such as bullet trains can be slowed, nuclear power plants in potential power outage areas as well as those at risk for damage can be shut down in minutes to hours, and chemical plants can be shuttered in one to two days.

- Rapid isolation of reactive vessels and process plants is considered the most effective step toward preventing loss of containment or limiting the size of loss for hazardous chemicals. Three options for achieving emergency shutdown include:

\footnotetext{
13 "Passive Control For Seismic Protection Of Critical Components In Industrial Process Plants," Ciampi et al., Proc. of the 13th World Conference on Earthquake Engineering, 2004, www.iitk.ac.in/nicee/wcee/article/13 1836.pdf, accessed May 4, 2011.
} 
- Manual valves - This is the most time-consuming option, it may place operators in danger, and the valves may only be fitted for maintenance work (thus they may not provide the most effective means for achieving emergency isolation). ${ }^{14}$

- Auto process trips or shut-off valves- May not provide a tight shut off. Such valves must also be fireproof.

○ Remotely operated shut-off valves - These can be automatic or manual.

- Install shelters - If shelters have been installed prior to the event notification, injuries and deaths would be reduced by making it possible to evacuate to a safer place in the time available. Otherwise, facilities and structures should be identified that can be used as emergency shelters.

- Evacuate people - If the following improvements are made to the warning systems and evacuation capabilities, injuries and fatalities could be reduced.

- Improve warning systems by using new technologies in new ways - text broadcast to all within cellular towers that are in the area at risk with a pre-scripted instruction. Cellular towers have the capability to broadcast voicemail or text messages to visible users. The primary issue is bandwidth, which renders text messaging the more viable option, but there will still likely be a bandwidth issue. Warnings will need to be issued in waves and there would need to be a way to prevent nonemergency system uses of the bandwidth. Emergent calling behavior will tie up cell towers.

- Improve population evacuation capability - Drill, train, and increase compliance among the citizenry. Create in situ earthquake/storm shelters in the riskiest buildings and provide an exit in every classroom. If these improvements are in place before the event notification occurs, injuries and deaths can be reduced for the population at risk.

- Teach individuals what to do - To reduce injuries and deaths, drill and train on the recommended actions to take to minimize personal risk in the event of an earthquake. ${ }^{15}$ If citizens cannot evacuate to a shelter, there are actions that can be taken to reduce the likelihood of injury or death.

- Don't turn off (e.g., to start a maintenance procedure or test) any infrastructure that may aid in emergency response (electric power, telecommunications).

- Increase communications capacity for emergency services (stop incoming calls) as there will be dependencies that impact the warning system. (The warning may produce a "calling event.")

- Stop traffic from entering multi-level highways and bridges (This action would require new, safe mechanisms to occur safely in a matter of seconds.)

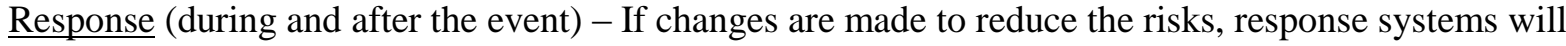
change. Otherwise the only way to reduce the consequences (other than those noted above) is to reduce response and recovery times and increase response and recovery capacities.

\footnotetext{
${ }^{14}$ Emergency Isolation of process plant in the chemical Industry," Health and Safety Executive Office, 1999, www.hse.gov.uk/pubns/chis2.pdf, accessed May 4, 2011.

${ }^{15}$ "Protect Yourself During Earthquake Shaking - Drop, Cover, and Hold On," Southern California Earthquake Center, University of Southern California, 2008, http://www.earthquakecountry.info/roots/step5.html, accessed May 4, 2011.
} 
- In an emergency, chemical plants have processes to reduce the risks. Some chemical production processes (such as those associated with polymer production) are referred to as runaway reactions. Runaway reactions are generally exothermic and may become unstable, releasing large amounts of energy and thereby causing unsafe conditions. Sometimes these processes will be doused with water in an attempt to control the reaction. Another mitigation strategy for addressing these reactions is that some plants have emergency safety dumps. ${ }^{16}$ In these dumps, the chemicals can safely be disposed of and contained. The time required to do so would depend upon the volume of chemical being disposed.

- The National Infrastructure Simulation and Analysis Center (NISAC) developed a Dynamic Prioritization Methodology (DPM) for hurricanes and earthquakes. The DPM is a multistep process that incorporates incident-specific conditions and data into a rapid, systems-based, risk-analytic framework to provide a prioritized list of actionable infrastructure restoration steps for application by disaster-recovery decision-makers. The DPM process considers competing and cascading objectives related to casualty minimization, public health and safety maximization, and economic cost minimization, over a time horizon under which restoration efforts will be implemented. ${ }^{17}$

\section{Question 3: How much warning time is needed?}

The time required depends on the actions that could be taken and the systems involved.

- Evacuation (for able-bodied and prepared individuals and groups) - People can duck and cover in a few seconds, provided there is adequate space nearby under desks or tables. People can exit a building in minutes. People can leave an area by foot or vehicle in minutes to hours (depending on such variables as size of area, proximity to boundary, mode of transport and congestion/available capacity of pathway). People can leave a city in days.

- Relocation - A population can be relocated over months to years.

- Automatic controls -Switches can activate in fractions of a second. Automatic valves can close in seconds. Traffic can be re-routed to its destination in minutes to days, depending on the system and conditions (amount of congestion and retry behaviors).

- Safe shutdown processes-Can take seconds to hours to days, depending on the system.

The chemical sector provides an example for evaluating the amount of time needed for safe shutdown of hazardous processes. Because of the high degree of variability of chemicals produced by the chemical processing sector, there is a great deal of variability in plant designs, manufacturing processes, and emergency responses plans. It is therefore difficult to generalize about emergency response processes across the entire sector. However, some rules of thumb do exist:

- In general, chemical production facilities (especially petrochemicals) will halt operations 4872 hours in advance of a hurricanes landfall. This protective measure is presumably intended to prevent hard shutdowns that could result from loss of power or damage to the facility. This action is intended to ensure containment of potentially toxic chemicals and allow evacuation of employees.

\footnotetext{
${ }^{16}$ Informal telephone conversation with ABS Consulting staff.

17 “ K.L. Stamber, M.S. Aamir, R. Aguilar, R.G. Knowlton, T.J. Brown, and J.A. Jones, "Foundational Methodology to Support Infrastructure Decision Analysis: Methodology Development Extension for Earthquakes," 2010 Sandia National Laboratories Report SAND2010-7108, Albuquerque, NM.
} 
- $\quad$ Shutting down processing operations cannot be done rapidly. Safely shutting down all operations generally requires at least 24 hours.

- Chemical processing facilities have emergency response plans to address a set of hazardous scenarios. It is likely these plans address a range of scenarios that include no-notice, shortnotice, and advanced notice events. Emergency responses will vary by plant and by scenario. These plans are generally filed with Local Emergency Planning Committees. ${ }^{18}$

\section{Question 4: What is an acceptable confidence level? (Encompasses the questions what is the impact of uncertainty and what is the cost of false alarms?)}

The answer to this question depends on what is considered an acceptable risk (expressed as a relationship between probability and consequence). Event notifications (which are certain) don't provide certainty in the outcomes. Hurricane warnings provide relatively predictable responses in the energy, chemical, and emergency preparedness sectors, but not in the responses of individuals to evacuation notices for areas and cities.

The consequences of false alarms for tsunamis are similar to those for hurricanes, because of the similarity in the actions that can be taken. The regions impacted and total costs (lives, injuries, dollars) will differ from event to event. Each type of action has different types and potential magnitudes of consequences in the event of a false alarm:

- Stop a hazardous process - it is expensive, it takes time to restart it, and there is lost revenue each time.

- Evacuate a building - Delayed productivity, possible reduction in compliance with evacuation orders the next time an alarm is sounded, and some likelihood of accidents (leaving processes unattended, congestion, tripping).

- Evacuate an area - Lost or delayed productivity, possible accidents and injuries due to traffic congestion, and possible reduction in compliance with future evacuation orders (until the time after something bad happens).

- Evacuate a city - Can it be done? It has the same risks as evacuating an area; but with increased magnitude (higher probability of failure and greater numbers of people impacted).

The cost of false alarms for earthquakes also depends on the actions that can be taken. Assuming that the only viable alternative to the long-term warnings provided by USGS, are event notifications that provide less than 30 seconds to take action; the costs will be due to disruptions of automated processes (switches or valves closing that must be reset) and people interrupting normal activities to move to safer locations. There could be accidents if people leave hazardous processes running unattended or suddenly change direction in response to the warning. Training and exercising behavioral actions should decrease the risks by making the actions more predictable and safer.

\footnotetext{
${ }^{18}$ Informal Telephone Conversation with ABS Consulting staff.
} 
If alarms are used, very quick approximations of magnitude and epicenter location and depth are used to inform the actions (e.g., stop all bullet trains). Improving the estimates of earthquake characteristics; mapping the characteristics to specific types of damage, locations of the damage, and actions needed to reduce the risks - all while keeping the calculation time very short - might be one of the only ways to reduce false positives and improve outcomes for events for which the costs of false positives are high or for which false positives might lead to low compliance or no action when action is required to save lives. 


\section{Key Issues}

There is an early warning system for earthquakes - but it is a prediction with temporal, spatial, and magnitude uncertainty. It is a difficult risk quantification, communication, perception, and mitigation problem. If an alert system could be developed, it might reduce the temporal uncertainty, but it is not clear that it would reduce the magnitude or spatial uncertainty. There is also an event notification system for earthquakes and for tsunamis that may be triggered by the seismic event (Figure 1). Improvement in the event notification system would increase the time people have to move to a safer location (out of and away from multistory buildings, schools, auditoriums, or warehouses and into a shelter). Training could be used to reduce the time required for evacuations. New shelter-in-place systems could be designed and installed, building codes and building construction changes could be made to decrease the vulnerability to earthquakes and/or reduce evacuation times to seconds rather than minutes. Alarm systems based on improved damage and earthquake estimation methods could reduce some risks but further study is needed to quantify the risks and benefits. For example, although closing bridges might save lives, there are many factors that require further analysis to determine whether or not closing bridges would provide a net benefit. Bridges might provide an important evacuation capability or fast route for emergency services. Wrecks might increase with congestion. 


\section{References}

1. USGS Earthquake Hazards Program, http://earthquake.usgs.gov/hazards/, accessed May 4, 2011.

2. USGS Earthquake Hazards Program, http://earthquake.usgs.gov/hazards/, accessed May 4, 2011.

3. FEMA Hazus Program, http://www.fema.gov/plan/prevent/hazus/, accessed May 4, 2011.

4. Details on earthquake alarms: $\underline{h t t p: / / w w w . s d r . c o . j p / p a p e r s / 14 w c e e / 14 w c e e ~} \mathrm{p}$-wave alarm systems.pdf and http://www.sdr.co.jp/papers/14wcee/14wcee p-wave alarm systems.pdf, accessed May 4, 2011.

5. http://eqseis.geosc.psu.edu/ cammon/HTML/Classes/IntroQuakes/Notes/waves and interior.html, accessed May 4, 2011.

6. From Compression and Shear Wave Velocity Versus Depth in the San Francisco Bay Area, CA,

7. Schweig, E., J. Gomberg, and J. W. Hendley II, 1995. Whole Lotta Shakin' Goin' On. U.S. Geological Survey Fact Sheet 168-95.

8. NOAA National Hurricane Center http://www.nhc.noaa.gov/, accessed May 4, 2011.

9. National Hurricane Center SLOSH Model, http://www.nhc.noaa.gov/HAW2/english/surge/slosh.shtml, accessed May 4, 2011.

10. NOAA National Weather Service, http://www.nws.noaa.gov/, accessed May 4, 2011.

11. "Passive Control For Seismic Protection Of Critical Components In Industrial Process Plants," Ciampi et al., Proc. of the 13th World Conference on Earthquake Engineering, 2004, www.iitk.ac.in/nicee/wcee/article/13 1836.pdf, accessed May 4, 2011

12. "Tougher pipeline safety standards closer in California", Central Valley Business Systems Times, http://www.centralvalleybusinesstimes.com/stories/001/?ID=18072, accessed May 4, 2011.

13. "Passive Control For Seismic Protection Of Critical Components In Industrial Process Plants," Ciampi et al., Proc. of the 13th World Conference on Earthquake Engineering, 2004, www.iitk.ac.in/nicee/wcee/article/13 1836.pdf, accessed May 4, 2011.

14. "Emergency Isolation of process plant in the chemical Industry," Health and Safety Executive Office, 1999, www.hse.gov.uk/pubns/chis2.pdf, accessed May 4, 2011.

15. "Protect Yourself During Earthquake Shaking - Drop, Cover, and Hold On," Southern California Earthquake Center, University of Southern California, 2008, http://www.earthquakecountry.info/roots/step5.html, accessed May 4, 2011

16. Informal telephone conversation with ABS Consulting staff.

17. K.L. Stamber, M.S. Aamir, R. Aguilar, R.G. Knowlton, T.J. Brown, and J.A. Jones, "Foundational Methodology to Support Infrastructure Decision Analysis: Methodology Development Extension for Earthquakes," 2010 Sandia National Laboratories Report SAND2010-7108, Albuquerque, NM.

18. Informal Telephone Conversation with ABS Consulting staff. 


\section{Distribution}

$\begin{array}{llll}1 & 1138 & \text { Pablo Garcia } & 6920 \text { (electronic copy) } \\ 1 & 1138 & \text { Lori Parrott } & 6924 \text { (electronic copy) } \\ 1 & 1137 & \text { Andjelka Kelic } & 6924 \text { (electronic copy) } \\ 1 & 1137 & \text { Kevin L. Stamber } & 6132 \text { (electronic copy) } \\ 1 & 1138 & \text { Nancy S. Brodsky } & 6921 \text { (electronic copy) } \\ 1 & 1138 & \text { Eric D. Vugrin } & 6921 \text { (electronic copy) } \\ 1 & 1138 & \text { Thomas F. Corbet, Jr., } & 6924 \text { (electronic copy) }\end{array}$

1 MS0899 Technical Library

9536 (electronic copy) 